\title{
Memoria y pedagogización del mal-decir: una aproximación a los recorridos literarios que inventan mundos*
}

\author{
Memory and pedagogy of ill-speak: \\ an approach to literary journeys that invent worlds
}

Memória e pedagogização do mal-dizer: um a aproximação a os percorridos literários que inventam mundos

Fecha de entrega: 30 de agosto de 2012

Fecha de evaluación: 31 de octubre de 2012

Fecha de aprobación: 6 de diciembre de 2012

Wílmer Villa ${ }^{* *}$

\section{Resumen}

Este texto es el resultado de una investigación que busca indagar sobre las formas que adquiere la representación en las prácticas, sobre todo cuando se intenta dar una versión sobre los "otros", racializados como seres inferiores. En este caso, intento hacer una aproximación a la literatura que aborda lo indígena desde una visión que asume

* Este texto se nutrió del seminario doctoral que orientó el profesor Michael Handelsman: "Literatura, Mestizaje e Interculturalidad", dictado en el verano de 2010 en el Doctorado de Estudios Culturales de la Universidad Andina Simón Bolivar, sede Quito.

* Candidato a doctor en Estudios Culturales Latinoamericanos de la Universidad Andina Simón Bolivar, sede Quito. Profesor del Proyecto Curricular en Educación Básica con Énfasis en Humanidades y Lengua Castellana de la Universidad Distrital Francisco José de Caldas y de la Maestría en Educación de la Universidad Pedagógica Nacional. Correo electrónico: villaw@hotmail.com 
esta tematización bajo una estrategia consciente o inconsciente de la suplantación del lugar de los otros. La aproximación que se hace actúa en el caso específico y no como una generalización proyectada sobre toda la literatura de este tipo; es más una apuesta por hacer otra lectura, llegando a una provocación de lo naturalizado por el canon que establece un patrón de clasificación en la producción. El texto se encuentra estructurado en cuatro apartados: el primero aborda lo fijado a través de imaginar lo colectivo; el segundo entra a mirar las estrategias de orientación; el tercero examina el problema de la invención; y el cuarto, el encierro de la memoria, muestra lo indio como cadena de sustitución en la literatura.

Palabras clave: invención, mal-decir, acción vehiculante, rejillas de apropiación, cadena de sustitución.

\section{Abstract}

This text is the result of a research that seeks to inquire about the ways that representation takes practice, especially when trying to give a version of the "others", racialized as inferior beings. In this event, I try an approximation to the literature that approaches the native from a viewpoint that assumes this issue under a conscious or unconscious strategy of impersonation of the place of others. The approach made acts in the specific event and not as a generalization projected on all this type of literature; is more of a commitment for another reading, reaching a provocation of the natural by the canon that establishes a classification pattern in production. The text is structured in four sections: the first one deals with the fixed by imagining the collective; the second looks at orientation strategies; the third examines the problem of invention; and the fourth, the memory lock up, shows the native as a substitution chain in literature.

Keywords: invention, ill-speak, binding action, appropriation grid, substitution chain. 


\section{Resumo}

Este texto é o resultado de uma pesquisa que procura indagar sob as formas em que adquire a representação nas práticas, principalmente quando tenta-se dar uma versão sob os "outros", racial içados como seres inferiores. Neste caso, tento fazer uma aproximação à literatura que aborda o indígena desde uma visão que assume esta temática sob uma estratégia consciente ou inconsciente da suplantação do lugar dos outros. A aproximação que se fez atua no caso específico e não como uma generalização projetada em toda a literatura deste tipo, é mais uma proposta de fazer outra leitura, chegando à uma provocação do naturalizado pelo cânon que estabelece um patrão de classificação na produção. $\mathrm{O}$ texto encontra-se estruturado em quatro secções: a primeira aborda o fixado através de imaginar o coletivo, a segunda entra para dar uma olhada nas estratégias de orientação; a terceira examina o problema da invenção; e a quarta, o encerramento da memória, mostra o índio como cadeia de substituição na literatura.

Palavras-chave: invenção, mal-dizer, ação, portador, grades de propriedade, seqüência de substituição.

\section{Fijando contenidos para imaginar lo colectivo}

En América Latina y el Caribe, la vehiculización de los relatos fundacionales ha sido posible a través de una intervención pedagógica que corresponde al interés de las élites nacionales de fijar los contenidos culturales que actuarían a favor de los procesos de sujeción de las personas en un marco de representación común. Esto ha asegurado la construcción de lo nacional como una orientación humana de larga duración ${ }^{1}$, lo cual generaría el sentido colectivo formado a través de las costumbres, tradiciones, valores y prácticas compartidas. Es así como las elaboraciones que ligan los contenidos de identificación y formalización de la identidad grupal se producen al tenor del agenciamiento discursivo que pasa a representar a los pueblos y naciones. Todo

1 Larga duración es entendida en términos de Braudel. Para Guerrero (2005), Braudel "es consciente del carácter multidimensional del tiempo, pero lo reduce a tres dimensiones: el lento (el de la geohistoria), el no tan lento o larga duración (el de las estructuras); el rápido (propio de las coyunturas, los individuos y los acontecimientos)" (p. 125). 
esto actúa en la creación de un sentimiento gregario que actúa en el posicionamiento y defensa de un "nosotros", conveniente de alimentar a cada momento en la vida pública y privada de los ciudadanos; proceso que conllevó el establecimiento de las narrativas de afirmación y sujeción a los contextos y las experiencias.

No es exagerado afirmar que los procesos de aseguramiento de lo nacional en América Latina se produjeron de forma guiada e intencionada. Para constatar esto, basta solo con revisar el modo como se produce el sentir generalizado de lo nacional, convertido en un lugar común, a partir del cual se posiciona la pertenencia a un contexto demarcado por una territorialidad. Esta, a su vez, es construida históricamente a través de prácticas lingüísticas, dinámicas de aprehensión cognitiva del espacio y celebración de rituales y festividades memorables de promoción selectiva. Frente a estos procesos de aseguramiento de lo nacional, conviene decir que los modos de sujeción de las personas en los últimos tiempos han cambiado por la influencia de las mediatizaciones. A través de estas, los flujos culturales se van alterando, más directamente por la explosión de imágenes venidas de los contextos de la globalización, las cuales inciden en los modos como se configuran las identidades. Allí, la manipulación del deseo y el rompimiento de las relaciones cara a cara se convierten en el principal ingrediente de incidencia en la translocalización del sentido, que ya no deriva de la experiencia directa sino de las mediatizaciones.

Para asegurar la producción de la territorialidad se contaría con la incidencia de las instituciones sociales, asumidas como "un conjunto de normas, reglas, valores y pautas de comportamiento que son obligatorios para los individuos de un grupo o para las relaciones con otros grupos, y que pueden permitir sanciones en caso de infringirse" (Lozano, 2000, p. 36). Estas actúan en la reproducción cultural que garantiza el establecimiento de lo monocultural, entendido como un proceso de doble acción: la primera consistente en fijar lo simbólico y lo material; la segunda se da con las dinámicas de exclusión de los contenidos que son excretados por la cultura desde el centro hacia la periferia.

Los imaginarios, puestos en relación con las instituciones sociales, actúan en la invención de un orden simbólico que tiene como tarea la estabilización dentro de un marco común de representación por donde circulan los contenidos culturales. Son las instituciones sociales una instancia simbólica que influye en la organización y regulación de la experiencia cotidiana, a partir de la legitimación y distribución de las producciones colectivas. Estas son el resultado de relaciones de poder ejercidas 
por los grupos privilegiados, que se encargan de direccionar la acción vehiculante de los contenidos.

Lo monocultural surgió a partir de la dinámica de proyección-condena de lo focalizado que se reprodujo bajo el renombre de la identidad nacional; dinámica que se mantiene por largo tiempo a través de las expresiones conjugadas y expuestas como propias. Por este motivo, lo monocultural aparece como un dispensador de contenidos que eran privilegiados y promocionados por las élites bajo un culto fiel al molde viajero de épocas inmemorables. Para abordar la categoría "nación” en términos de una relación-tensión con lo monocultural, utilizo la definición de Anderson (1997), que la considera como "una comunidad política imaginada como inherentemente limitada y soberana” (p. 23). Esto quiere decir que la nación se establece por medio de un vínculo natural, restringido y autónomo, que se hace posible por medio del hecho de la imaginación y de todos sus derivados, en tanto productores de imágenes colectivizadas a lo largo de la historia.

La nación se vuelve "limitada", según Anderson (2007), por cuanto todas las personas que la integran se enfrentan al impedimento de conocerse en su totalidad; aun así, ellos producen y reproducen las imágenes que alimentan la imaginación:

Es imaginada porque aun los miembros de la nación más pequeña no conocerán jamás a la mayoría de sus compatriotas, no los verán ni oirán siquiera hablar de ellos, pero en la mente de cada uno vive la imagen de su comunión (Anderson, 2007, p. 23).

Imaginar se relaciona con los procesos de la mente y puede ser resultado de lo inmanente, así como de las "mediaciones culturales", producidas en el contexto y las interacciones entre las personas. Frente al acto de imaginar, así como frente al imaginario, Occidente guardó una distancia de condena que durante un tiempo condujo a la subvaloración, relegando la imaginación solo a las artes, donde su uso proveía una desviación fantasiosa de la realidad.

La imaginación, lo imaginario, evoca en su acepción corriente la producción de ilusiones, símbolos, quimeras, evasiones siempre de la dura realidad de los hechos. El mundo imaginario, así definido por la tradición estética o 
científica, queda reservado al dominio de la literatura, de la poesía o de las artes (Colombo, 1989, p. 7).

Cuando se refiere la imaginación en el acto de representar lo colectivo, se entra en el terreno de la historia, en especial en la escuela de las mentalidades, que considera la cotidianidad inmediata de los pueblos, naciones y comunidad a través de dar con los imaginarios colectivos. En este caso, el interés por el devenir de los pueblos facilita el estudio de las articulaciones, las emergencias y las modificaciones de las visiones de mundo que cambian en el tiempo y espacio:

El concepto de visión de mundo presentado aquí es muy similar al famoso concepto de laberinto de Anthony Wallace (1970, p. 14), que lo definió como "imagen mental" que consta de residuos cognitivos de la percepción [...], usados por su poseedor como una representación verdadera y más o menos compleja de las características operativas de un mundo real (Palmer, 2000, p. 147).

Al momento de entender las dinámicas de producción cultural se hace necesario relacionar los imaginarios, las visiones de mundo y las instituciones sociales. En la figura 1, en cada ángulo se encuentra el contenido particular que representa el proceso de relación permanente.

Figura 1. Relaciones en la dinámica de producción cultural

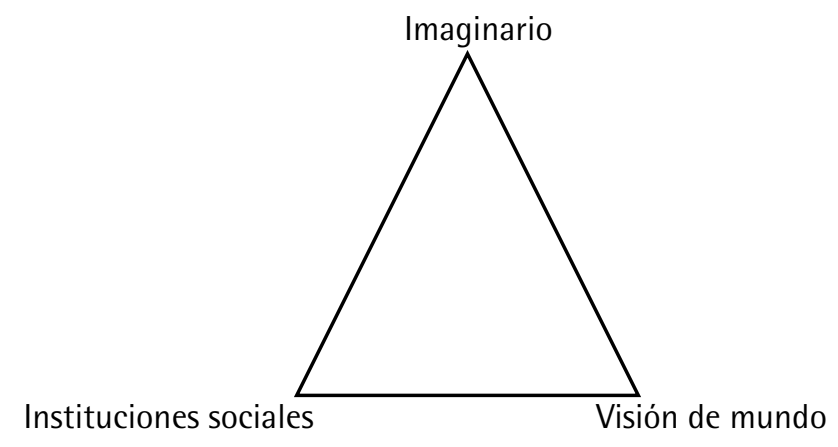

Fuente: autor 
A propósito de los imaginarios, señala Abril (2007):

Castoriadis (1975 y 2001) ha defendido vigorosamente que toda sociedad es una constitución de su propio mundo y de su propia identidad, y en esa construcción tiene un papel fundamental el imaginario social: los imaginarios son, pues, expresiones de la creatividad y del sentido innovador de las sociedades, sobre todo en lo referido a la génesis de nuevas instituciones (p. 60).

Los imaginarios como instancia que alimenta la visión de mundo, puesta a circular a través de las instituciones sociales, actúan en la invención de un orden simbólico, el cual tiene como tarea la estabilización de las colectividades. Todo esto se produce dentro de un marco común de representación en el que circulan los contenidos culturales. Es de apreciar que esta triada, conformada por los imaginarios sociales, la visión de mundo y las instituciones sociales, se convierte en una instancia simbólica de estabilización por medio de la cual se organizan y regulan las experiencias cotidianas. Por ello, estos elementos inciden en la legitimación y distribución de las producciones colectivas, resultado de relaciones de poder ejercidas por los grupos privilegiados, que se encargan de direccionar la acción vehiculante de contenidos.

El hecho de considerar la anterior situación conllevó a formular la siguiente pregunta: ¿bajo qué dinámica de acción vehiculante se producen los significados que son concebidos como representativos de una colectividad? En este caso, no busco agotar la pregunta con una repuesta certera; solo pretendo, a través de ella, abordar los direccionamientos de la acción vehiculante de contenidos, la cual propongo como una estrategia de orientación para la fijación de contenidos que guían la voluntad colectiva de las personas dentro de un establecimiento legitimador de los comportamientos y discursos.

\section{Abordando las estrategias de orientación}

El acto de imaginar comunidad se produce a partir de la puesta en funcionamiento de los

mecanismos de selección que intervienen en el proceso. Si se piensa, por un lado, en el archivo, el museo, la enciclopedia o incluso en la historia de la literatura 
[...], todo cabe y todo se conserva [...] En este caso, se pone de manifiesto la labor de selección que exigen los programas y las prácticas (Sullà, 1998, p. 11).

Esta consideración guarda correspondencia con lo sostenido por Anderson (1997), que compromete la novela, el periódico, el censo, el mapa y el museo en el acto de representar la comunidad imaginada. Se trata, en estos casos, de la selección, fijación y distribución de contenidos que actúan en el agrupamiento particular de la nación.

En el XVIII, la novela y el periódico se convirtieron en una instancia de "aprehensión del tiempo", en tanto "proveyeron los medios necesarios para la 'representación' de la clase de comunidad imaginada que es la nación" (Anderson, 1997, p. 46). Para la elaboración de la novela se contaría con la técnica de reflejar la realidad a través del acto de imaginarla y operarla a través de los libros que empezaban a circular de forma masiva. De este modo, los libros surgen como el primer producto industrial que se impone por medio del "imperialismo impreso", el cual viene a representar una descentración de las comunidades religiosas y dinásticas. En definitiva, el libro vendría a acompañar el surgimiento de la nación, específicamente en el acto concreto de fijar una concepción de tiempo: "Es claramente un instrumento para la representación de simultaneidad en 'tiempo homogéneo, vacío"' (Anderson, 1997, p. 47), llegando a ser proyectado como un tiempo que es igual para todas las personas. En resumidas cuentas, en la instrumentalización del tiempo, las acciones humanas se orientan de acuerdo con los medios para alcanzar los fines.

En América Latina, la "proyección imaginada”, vista como la estrategia que aseguraba la reproducción de las narrativas fundacionales de la nación, se produjo por medio de la cultura letrada que compartía un pequeño grupo de criollos ilustrados, a los que Anderson denominó los "pioneros criollos". Estos “adoptaban la forma de una clase media inquieta y una jefatura intelectual que trataba de agitar y dirigir las energías de las clases populares en apoyo de los nuevos Estados" (Anderson, citado en Villa y Villa, 2008a, p. 134). La proyección de los relatos fundacionales de la nación por parte de las élites letradas al resto de la población demandaba una dinámica de acción vehiculante de los contenidos que pasaban a representar la colectividad; para lograr este fin, idearon unos discursos que eran pedagogizados y reforzados a través de las "rejillas de apropiación”, que según Saldarriaga, Sáenz y Ospina (2007) eran "un conjunto de [...] filtros estratégicos de naturaleza política, religiosa y filosófica (p. 4). 
Se puede afirmar que las "rejillas de apropiación" se articularon a partir de la producción de unas narrativas maestras que actuaron en la clasificación y encierro de las experiencias de los otros, los cuales eran vistos como seres inferiores, seres carentes de razón, seres que amenazaban el orden racial que debía gobernar en la república y en la nación. Se puede afirmar que las "rejillas de apropiación" se convertirían en generadoras de los discursos de condena, de ahí que estas producciones lingüísticas incidieran en la reproducción de lo que, en mis investigaciones, he llamado "el maldecir": un decir mal, un decir inapropiado que conlleva la muerte de la sonoridad de los otros; sonoridad que se traduce en discurso, representación y acción.

El mal-decir es la condena, es el hecho de inhabilitar a los otros, que no pueden decir nada desde ellos mismos, sin pasar por los discursos dominantes de los que hablan o dicen de nosotros-otros. Esta dinámica de imposibilitar a los cuerpos de las personas se ve acompañada por las estrategias de desacreditar, a través de la deformación $n^{2}$ que conduce a las personas a desalojar su ser. Se trata de propiciar una acción de huida de su propia autoimagen acústica, corporal, epistemológica, espiritual, cultural y política; en cierto sentido, el otro no puede ser lo que es, pues solo es el resultado de los procesos de traducción que se generan por medio de una hermenéutica monotópica ${ }^{3}$. En este contexto, el yo instaura un orden explicativo que se sustenta desde la aplicación de un "código arbitrario de interpretación", empleado para representar el comportamiento de los otros, reducidos, negados y distorsionados.

Al momento de considerar el mal-decir y su incidencia en la producción de una secuencia de fijación del lenguaje y acción, se hace necesario mirar las manera como se da la representación, sobre todo cuando se intenta afrontar los procesos y las experiencias relacionadas con la mismidad, otredad y alteridad; en este caso, debe tenerse en cuenta la política de nombrar o asignar nombre. El referente más lejano que Occidente tiene sobre el hecho de dar nombre se encuentra en el Cratilo de Platón (Calvo, 1999). En este texto se presenta un diálogo entre Hermógenes y

2 En el estudio que he venido haciendo del racismo a través del mal-decir he observado cómo se ha configurado históricamente una dinámica que deja a los otros y otras por fuera de cualquiera posibilidad de construcción de un proyecto de dignidad. Esto se hace a través de lo que he denominado como las 3D, es decir, deformar, desacreditar y desalojar, que se dan como parte de un continuo de negación y actúan de forma relacional, es decir, se encuentran siempre asociadas entre sí; no tienen un orden, pero sí una relación permanente.

3 Esto lo tomo de la discusión que plantean Boaventura de Sousa Santos, al igual que Walter Mignolo, quienes a su vez la retoman de Raimon Panikkar, filósofo español de origen indio, que es el primero en poner la discusión sobre la necesidad de una hermenéutica pluritópica. 
Cratilo, donde el primero defiende si los nombres son convencionales y el segundo, si son naturales. Lo que deja ver toda esta conversación es el papel que cumplen los nombres en la representación de las cosas, llegando al punto de poner en relieve la pregunta: ¿quiénes son los que dan lo nombres? Son los filósofos quienes cultivan la actividad de dar nombre, es decir, la onomaturgia, por lo que son llamados también los "onomaturgos". Ellos, en últimas, son los que ponen los nombres y a través de una política en las formas de llamar las cosas inciden en la representación de los objetos, las personas y los lugares; ellos son las personas encargadas de vehicular los contenidos de afirmación de una realidad.

Las denominaciones que activan los contenidos bajo los cuales asignamos sentido a las cosas son el resultado de representaciones y acciones que devienen de un relacionamiento entre las personas. En este caso, la representación se convierte en un producción que afirma las relaciones asimétricas de poder, en la que un grupo de personas privilegiadas dominan la escena de representación a través de un "agente especializado" que se fue configurando históricamente y que en la modernidad juega un papel central en las prácticas de representación:

El agente especializado de la modernidad es el actor del discurso disciplinar quien legitima, vigila y controla la producción del conocimiento, dentro de una organización e institucionalización de las formas de decir que son compartidas por las comunidades científicas; es el actor que inventa y adecúa los comportamientos de los otros a la forma de ver el mundo de ellos. En este caso, se hacen evidentes dos formas de representar comúnmente a los otros desde un ellos predominante. "Una es negar o ignorar la distancia cultural, asimilar a los otros a nosotros o a nuestros vecinos, mediante la utilización de la analogía, tanto si el empleo de esta es consciente, como si es inconsciente. El otro es visto como reflejo del yo" (Burke, 2001). Es la reducción de las diferencias culturales a la compresión del yo que representa el centro en la construcción de los modos de decir que se ponen a circular sobre los otros. Es la analogía que hace inteligible lo exótico lo que domestica (Villa y Villa, 2008b, p. 63).

Tanto la política de dar nombre y la representación propician, en algunos casos, la formación del mal-decir, el cual se encarga de fijar contenidos que actúan en la cotidianidad inmediata de las personas. De ahí que la representación se origina en el relacionamiento del yo con los otros u otras, traídos al centro de representación por 
medio de "la analogía" o de "la invención”. En este caso, la prolongación se convierte en una forma de captura de los contenidos de los otros, vistos como seres exóticos, producidos y reducidos a las ficciones del un yo que se proyecta por encima de todo lo que compone la existencia:

El otro como una prolongación del Yo solo existe en tanto es percibido desde lo familiar, desde las formas de habituación o naturalización de las costumbres que se quieren o se hacen en el otro, no importa que la cuestión de adecuar a los otros sea un acto de violencia, de silenciamiento o invisibilización de lo que realmente es como humano. Según Peter Burker, la segunda forma de representar a los otros tiene que ver con la invención. "Consiste en la invención consciente o inconsciente de otra cultura opuesta a la propia, de ese modo convertimos en 'otros' a nuestros congéneres', que son vistos en la distancia como seres extraños que no hacen parte de nosotros, sino que son parte de los otros, recreados a través de la construcciones discursivas que hacen ellos (Villa y Villa, 2008b, p. 63).

Las formas de representar por "analogía" e "invención" actúan en el acto de formación y proyección generalizada de los contenidos culturales de los otros que son distorsionados a través de las creaciones del yo. De ahí que lo familiar se pone en función de la explicación de lo extraño, o lo no conocido se convierte en "fuente de todo mal": es la "la demonización del otro, su transformación en sujeto 'ausente', es decir, la ausencia de las diferencias al pensar la cultura" (Duschatzky y Skliar, 2001, p. 188). La formación de mal-decir se fue dando a lo largo del tiempo de forma universal y específica, llegando a convertirse en una invención generalizada que actuó en la orientación de las estrategia para la negación de los otros, clasificados de forma distante y sin ninguna respuesta a sus particularidades existenciales. Un caso que vendría a reflejar esta situación en el contexto mundial se encontrará en el relato de Noé, cuando uno de sus hijos fue castigado por desobediente con el oscurecimiento de su cuerpo. A propósito de esto, Mignolo (2003) analiza la emergencia, modificación y mantenimiento de la "colonialidad global":

El primer conjunto categorial es el de raza, trabajo y género/sexualidad. La cuestión del género y la sexualidad se estructuró, en la civilización occidental, en el relato bíblico, en la historia de Adán y Eva, y también en la historia del diluvio y en el hecho de que los tres descendientes de Noé fueron varones (Jafet, 
Sem y Cam). Por el primero, la estructura ética de la relación hombre-mujeres se asienta en la relación de la pareja, masculino-femenino. Por el segundo, la estructura geopolítica del mundo se asienta sobre el valor humano que se asigna a casa uno de los tres hijos de Noé (...): a Cam, él más despreciable, se le atribuya África; a Sem, quien ofreció esperanza y dio signo de buen comportamiento, se le identifica con Asia, y a Jafet, el aliento, la expansión y la visión de futuro, se lo asienta en Europa. "América”, nombrada así en honor de Américo Vespucci, toma una $a$, se feminiza, para coordinarse con Asia y África, las cuales tienen como patrones cristianos dos hijos varones de Noé. En cuanto al trabajo, la esclavitud fue, desde Aristóteles, uno de los temas fundamentales de consideración en la teoría política y económica que llega hasta las célebres páginas de Hegel sobre el amo y el esclavo, donde reflexiones sobre la liberación de una clase social, la burguesía (p. 45).

Este análisis que hace Mignolo sobre la génesis global de la colonialidad a través del relato fundacional de la biblia se convierte en un claro ejemplo del mal-decir, o un decir mal sobre los otros que son despropiados de su autoimagen; es más la condena o clausura que deja por fuera de la historia a la política y a cualquiera posibilidad de construcción su sí mismo (self). Para ejemplarizar el mal-decir como una formación histórica específica de invención generalizada que actúa en la orientación de estrategias para la negación de los otros, encerrados y clasificados a través del punto de vista dominante, a continuación menciono tres casos que se fueron formando en el periodo de emergencia de la República en América Latina, más específicamente en la región andina, cuando las élites nacionales se idearon unos modos de decir para desalojar a los otros racializados. En Bolivia, el grupo de criollos dominantes utilizó la expresión “pueblo enfermo” (Arguedas, 1937 [1909]); en Colombia, “raza degenerada” (Sáenz, Saldarriaga y Ospina, 1997), y en Ecuador, "raza vencida” (Guarda y Villa, 2010). Las tres formas de nombrar en esta parte del Abya Yala ${ }^{4}$ refleja la profunda "desconfianza" que las élites le tenían al pueblo, tal como sucedió en el caso colombiano:

La mayoría de los pedagogos activos nacionales consideraban necesario adecuar los nuevos saberes, instituciones y prácticas a la situación del país. Pedagogos reformistas como Miguel Jiménez López, Rafael Bernal Jiménez y Gabriel

4 Nombre asumido por varias organizaciones indígenas de varios paises desde la década de los ochenta y que en lengua cuna quiere decir "tierra en plena madurez". 
Anzola partían de una imagen pesimista del estado de la raza y de la infancia colombiana, pues las consideraban afectadas por profundas y gravísimas patologías físicas, mentales, morales y sociales, y por tanto privilegiaron opciones de reforma educativa de carácter remedial o "defensivo". Se conformaría así un doble movimiento; por una parte, el salto a lo moderno, y por otra, detener el retroceso de la raza, su involución hacia un pasado primitivo y bárbaro. Inspirados en las teorías de la evolución de la especie, la preocupación central de estos intelectuales fue la biología de la raza. Según ellos, de su defectuosa conformación se derivaban los males intelectuales, morales y sociales del país (Sáenz, Saldarriaga y Ospina, 1997, p. 11).

Aunque en este texto no pretendo hacer una análisis exhaustivo sobre las tres formas específicas de construir el mal-decir en esta región del mundo, lo que busco es poner los tres ejemplos como una instancia generadora de condena histórica; es decir, tanto la construcción de "pueblo enfermo", "raza degenerada" y "raza vencida" se posicionan como una estrategia de contención y debilitamiento de la potencia libertaria de aquellos que padecían la dominación y la explotación de un sistema colonial y neocolonial. Los tres tipos de denominación se articulan a una forma de aprehensión del tiempo y espacio que tiene como meta la construcción de lo nacional, dejando al margen los pueblos y naciones originarias ${ }^{5}$, así como pueblos originarios de la diáspora africana.

Las tres formas de nombrar a los pueblos originarios de los Andes hacen parte de una estrategia de orientación y degradación de los otros racializados de manera negativa, lo cual se vería acompañado de la invención-adecuación de un orden excluyente continuo, actualizable por medio de una literatura nacional, la historia de promoción que recrea el relato de los vencedores, la medicina y su constante obsesión por la higiene y la patologización de los cuerpos anormales, la antropología sustentada en un patrón de medida antropométrico, la geografía anclada en el determinismo climatológico, la pedagogía y su disposición legitimadora desde el discurso de la sicología, la biología al encausar la explicación de las razas a través del darwinismo social y la depuración de la raza a través de los postulados eugenésicos. Todas estas narrativas maestras se

5 Esta alusión se articula a la reivindicación que se hace en las constituciones de Bolivia y Ecuador, en la que se exaltan y garantizan los derechos que tienen los pueblos y naciones originarias, muy diferente a la Constitución Política de Colombia, que habla de pueblos étnicos y comunidades étnicas, amparada en un derecho diferencial que se sustenta en el solo reconocimiento al mejor estilo multicultural. 
convirtieron en la barrera de detención y avance de las personas que supuestamente amenazaban el equilibrio social y la continuidad de los usos y costumbres de una cultura civilizada:

\begin{abstract}
Para este discurso sociobiológico, la configuración de una nación moderna y civilizada no era posible a corto o mediano plazo en un país calificado insistentemente como "bárbaro", "salvaje”, "enfermo", "débil", "atávico". Dentro del proceso de evolución de la especies, el país era considerado un pueblo joven y en formación; se trataba de una nación todavía en una etapa infantil, salvaje y anómala en comparación con las civilizaciones modernas. Se pensaba que la nación compartía todas las características de la infancia, de los enfermos y de los anormales: debilidad de la voluntad, dificultad para fijar la atención, poca capacidad de memoria, incontinencia física y psíquica, carácter instintivo y emotivo, fragilidad física y moral (Sáenz, Saldarriaga y Ospina, 1997, p. 5).
\end{abstract}

Los otros racializados pasaron a ser inventados desde las imágenes distorsionadas que lograron imponer las narrativas maestras y desde los "filtros de apropiación de la modernidad", que eran una forma de estabilizar el orden social a través de la construcción de unos moldes culturales, políticos, lingüísticos, económicos, espirituales, éticos y estéticos. Todo esto ha actuado como ingrediente que ha ayudado a conformar la historia de la nación en América Latina, sobre todo en países como Bolivia, Colombia y Ecuador, donde la subalternización es el continuo de reproducción de la dominación y explotación. Para Guha, "la presencia de lo subalterno demuestra que la nación no ha sido posible y que la historia de los proyectos nacionales es solo la autobiografía de una élite" (en Vich y Zavala, 2004, p. 103). De esta forma, la nación ha sido un invento monocultural para someter a las otras culturas a través del disfraz de la integración vía asimilación.

\title{
La recreación literaria: una invención de encierro de memoria que actúa sobre los otros
}

El arte, en general, acompañó el surgimiento de la nación en una clara invención formalizada por las élites criollas, que dominaron el escenario de la representación de lo nacional. En un principio, los ilustrados criollos sirvieron al proyecto político que conduciría a la estabilización de un orden social relativamente autónomo en las 
excolonias. Y hago esta aseveración por el complejo hecho de que los gobernantes, los artistas, los filósofos, los pedagogos y los historiadores, que se encargaban de cultivar las narrativas maestras, aún dependían de las producciones epistemológicas, lingüísticas, estéticas, éticas, jurídica y políticas que venían de los centros urbanos del otro lado del océano Atlántico.

Los ilustrados criollos se convirtieron en agentes de reproducción de una realidad que era organizada a través de la imitación de los usos, las costumbres y las instituciones de los europeos. Esto se convertía en la principal causa de penetración cultural: pese al hecho de haber dado su grito de libertad a comienzos del siglo XIX, las élites criollas siguieron con el continuo de la colonización en el interior de los territorios nacionales. Por este motivo, no se puede decir que en América la poscolonialidad haya ocurrido como parte de un hecho político que conllevó la transformación de las relaciones asimétricas entre centro y periferia:

Decir con razón que las guerras de independencia fueron seguidas por guerras de exterminio contra las poblaciones indígenas de Norte y Sur América, no acarrea el llamar a los discursos subsecuentes que justifiquen ese exterminio como no coloniales; solo significa que, desde la perspectiva indígena, el colonialismo no concluye cuando en sentido formal un estado particular se convierte en "poscolonial". Todo puede volverse una excepción si se observa con suficiente fijeza. Y necesitamos observar minuciosamente, pero también necesitamos aferrarnos a nuestra arraigadas generalidades, entre las cuales “discursos coloniales" es una de las más importantes (Hulme, 1996, p. 5).

Los otros racializados de forma negativa a través de la impronta del mal-decir, durante el proceso de la independencia y los tiempos posteriores a este acontecimiento, no vivieron un cambio sustancial que representara la superación del colonialismo; por el contrario, las transformaciones que se dieron seguían manteniendo, en el espacio y el tiempo de la nación, la dominación y la explotación: los indígenas y negros fueron sitiados por los discurso de integración, vía la asimilación a una cultura de centro que usaba como punta de lanza la castellanización, la evangelización, el urbanismo o la construcción de "buenos modales", a partir de la sumisión, la higiene y la regulación de las "buenas prácticas de aseo". Todas estas pretensiones por alcanzar una nación moderna se convertirían en una programática política, conducente a allanar las diferencias, es decir, la consecución de una entidad homogénea, libre de "la amenaza 
bárbara" de los indios y los negros; en cierto sentido, esta es una evidencia que deja entre dicho la poscolonialidad:

\footnotetext{
Unas de las maneras más frecuentes de confundir el término "poscolonial" es imaginar que el propio término sugiere de alguna manera, erróneamente, que el "colonialismo" ha quedado atrás, mientras todos sabemos bien que vivimos en un mundo marcado por el neocolonialismo (Hulme, 1996, p. 6).
}

Otro motivo que lleva a pensar que lo colonial no quedó atrás se relaciona con los descendientes de los nietos de los españoles, es decir, la gente nacida en el "nuevo continente", que actuaban y pensaban como españoles. Ellos en la península Ibérica no eran reconocidos como pertenecientes a la "madre patria" - a lo que ellos mismos se dieron a la tarea de alimentar como narrativa fundacional-; eran simplemente unos criollos, blancos-mestizos nacidos en las colonias. Esta posición de tener la mente fijada en España y los pies en América los hacía merecedores de una "conciencia contradictoria" que se manifiesta a través del profuso respeto y sentido de conexión con los europeos. Ello los llevaba a imitar o querer ser como europeos, pero a la vez tenían una realidad ante sus ojos: el convulsionado escenario político, jurídico-administrativo, económico y militar de las nuevas repúblicas.

El hecho de dejar atrás el pasado no representó la fundación de un nuevo tiempo y un espacio de convergencia o encuentro con lo excluido; en términos de Dussel (2004) se trató de "no incluir el potencial no incluido" (p. 201). Tal fue la situación que se generó para la época del nacimiento de la república y la nación, que algunos autores de la literatura y la filosofía llamaron la atención de lo que venía sucediendo: “Andrés Bello, al igual que José Martí, aducían que América Latina no tendría una literatura propia claramente definida, basada en prácticas locales que no imiten modelos europeos" (Yudice, citado en Villa y Villa, 2008a, p. 235). Esto viene a poner de relieve el problema del anatopismo que cultivaban algunos de los políticos, pensadores y literatos de este periodo en América Latina. Se trataba de gente que reproducía una "ceguera antropológica" (Rama, 1998) contra los referentes más cercanos de cultura. La categoría "anatopismo" es reintroducida en el terreno de la teoría crítica latinoamericana a través del libro Filosofía andina: estudio intercultural de la sabiduría autóctona andina, de Estermann (1988): 
El término "anatopismo", acuñado por Víctor Andrés Belaunde (1889-1966) en sus Meditaciones peruanas, quiere resaltar el carácter sumamente alienado de un pensamiento, en especial del latinoamericano, que "transplanta" simplemente la filosofía occidental en suelo (topos) americano, sin tomar en cuenta la propia realidad. Las élites latinoamericanas son en gran medida "anatópicas" no solo con respecto a su pensamiento, sino también a las formas culturales y el modo de vivir en general (p. 21).

La puesta en marcha de un pensamiento "anatópico" no solo afectaría la elaboración de la filosofía, sino también la literatura y en general el arte, así como todas las narrativas que encarnaban las llamadas "rejilla de apropiación de lo moderno". Esta predisposición del hombre americano a negar cualquiera posibilidad de fundar un pensamiento conforme los elementos propios de la tierra se daría a partir de las élites que durante el siglo XIX y gran parte del XX mantuvieron el control sobre la producción cultural. Al respecto, Estermann (1988) comenta, citando a Mariátegui:

En 1925, José-Carlos Mariátegui escribió: “Todos los pensadores de nuestra América se han educado en una escuela europea. No se siente en su obra el espíritu de la raza. La producción intelectual del continente carece de rasgos propios. No tiene contornos originales. El pensamiento hispano-americano no es generalmente sino una rapsodia compuesta con motivos y elementales del pensamiento europeo" [...] Víctor Andrés Belaunde acuñó para esta condición típica de la filosofía latinoamericana el término "anatopismo" [...], Augusto Salazar Bondy habla de una profunda "inautenticidad” y "alienación”, Leopoldo Zea de "servidumbre" y "dependencia", y Enrique Dussel la llama "ontología del centro" (p. 30).

Tanto la filosofía como la literatura han actuado en la consolidación de las prácticas de estabilización de un orden explicativo que ha incidido en la organización y consideración de la realidad en las naciones de América Latina. La estabilización como proceso de producción se encuentra asociada a las continuidades narrativas que hacen de lo fundacional algo compartido: "Mediante el discurso, los grupos dominantes pueden ejercer control en las mentes de los otros, sus representaciones culturales y sociales. Las instituciones o personas que ejercen el poder no ignoran la importancia del discurso" (Soler y Pardo, 2007, p. 193). 
El control cultural, como categoría de análisis, ha sido desarrollado por el antropólogo mexicano Guillermo Bonfil Batalla, quien entró a mirar lo propio y lo apropiado en relación con la "autonomía", "la dominación" y "la esperanza" que inciden en el desarrollo de los programas, estrategias y acciones que se dan en los contextos:

Por control cultural se entiende la capacidad de decisión sobre los elementos culturales. Como la cultura es un fenómeno social, la capacidad de decisión que define al control cultural es también una capacidad social, lo que implica que, aunque las decisiones las tomen individuos, el conjunto social dispone, a su vez, de forma de control sobre ellas (Bonfil, 1991).

Para lograr el control cultural se requiere de un sistema de educación, así como de una pedagogía que ayude a sostener el proceso de fijación a través de la pedagogización ${ }^{6}$ de los contenidos en contextos escolarizados y no escolarizados. En el caso colombiano, "la escuela ha constituido el vehículo más efectivo para popularizar el proyecto de modernización nacional basado en el mestizaje, ya que es una institución fundamental para el aprendizaje y la transmisión de valores" (Soler y Pardo, 2007, p. 195). El uso de la escuela como un "vehículo" para la puesta en común de contenidos por parte de las élites se ha dado en toda América Latina.

Las apuestas desarrolladas desde la institución social de la escuela se efectuaban por medio de la utilización de una pedagogía centrada en la metodología de la enseñanza de los contenidos que debían aprender los seres cultivados, a través de la disciplina, el orden y la sumisión. Mediante esta utilización se ponían en marcha los programas de instrucción pública que acompañaron la emergencia de la República y el adoctrinamiento de las personas que pasaban a ser merecedoras de la salvación:

Se trataba de educar a seres humanos iguales, sin tener en cuenta sus particularidades individuales ni la identidad cultural de los determinados grupos sociales; era un gran proyecto homogeneizador que pretendía modernizar el país mediante la castellanización y la alfabetización de las "degradadas razas" negra e indígena, para así facilitar su asimilación (Soler y Pardo, 2007, p. 195).

6 La pedagogización la propongo como parte de una estrategia política que conlleva una acción sostenida de movilizar contenidos, los cuales se vuelven significativos en la afirmación del lugar y los actores. Esta categoria se puede rastrear en trabajos anteriores que hemos realizado con el profesor Ernell Villa (2010). 
Fue así como se consiguió la formación de un pensamiento patriótico, el cual propendía a la unidad nacional y al patrimonio cultural. En el caso de Bolivia, según Franz Tamayo, la formación de un pensamiento de unidad se dio a través de una "creación de la pedagogía nacional" que propendía al mestizaje.

\section{Lo indio como cadena de sustitución en la literatura: una aproximación a la memoria que inventan mundos sobre los otros}

Lo indio, como una "cadena de sustitución" en la literatura, se manifiesta a través de la creación indigenista, la cual representaba a los otros racializados como seres inferiores o distantes, carentes, supuestamente, de una autonomía que los condujese a asumir "su mayoría de edad". En este caso, la tarea de quienes producían la literatura indigenista era la de traer al centro de representación a esos cuerpos extraños, y desde ahí hacer la invención escritural que ayudaba a formar la imagen literaria que les permitía hablar por los otros. De alguna forma, este ejercicio se constituía en un acto que conllevaba imposibilitar a los pueblos originarios del Abya Yala a agenciar su propia voz como actores históricos.

Frente a la aproximación que propongo hacer de las obras seleccionadas que hacen parte de la literatura indigenista, utilizo la categoría "cadena de sustitución", extraída del ensayo de Gayatri Chakravorty Spivak (2003): “Puede hablar el subalterno?”, en la cual utiliza la siguiente cita de Marx:

No pueden representarse ellos mismos: deben ser representados. Su representante debe aparecer simultáneamente como su señor, como una autoridad sobre ellos, y como irrestricto poder gubernamental que los protege de las otras clases y que les envía el sol y la lluvia desde lo alto. La influencia política [en lugar del interés de clase, toda vez que no hay un sujeto de clase unificado] de los pequeños propietarios campesinos por consiguiente encuentra su última expresión [la consecuencia de una cadena de sustituciones - Vertretungenes fuerte aquí] en la fuerza ejecutiva [Exekutivegewalt: personal inferior en alemán] subordinando la sociedad a sí misma (p. 310). 
En el centro de la discusión que nos presenta Spivak (2003) se encuentra el problema de la representación y su posibilidad de generar un tipo de agencia que lleve a posicionar la voz del subalterno. Esto tiene que ver con la representación en tanto delegación política, a partir de la cual se entra a interrogar el hecho de "hablar en favor de", lo cual no es un acto inocente, neutral y ajeno a la adscripción política de quien representa. De cierta forma, se trata de desnudar a quien pretende recoger los contenidos de la vida del otro, llegado a advertir sobre los riesgos que se corren cuando se da el acercamiento al otro, por medio de un artefacto escritural que acude en búsqueda de un alguien exótico y exotizado, para convertido "en la sombra del yo".

Todo esto, posiblemente, actúa como una usurpación ${ }^{7}$ del lugar que le corresponde al otro y a través de cual puede generar su propias representaciones literarias, de tal modo que se llegue a actuar sin producir un vaciamiento del sentido que se genera en el desenvolvimiento de la vida del otro inventado como el inferior, el diezmado y el resignado a vivir una vida que depende, en cierta forma, de la "sombra" creada y recreada de las relaciones desiguales que corresponden a la colonialidad. La literatura, en este caso, ayuda a constituir una imagen que viene de la imaginación literaria y pasa por los filtros existenciales de quien controla la representación, sobre todo si se tiene presente que el origen de la literatura en América "se dio como parte de un proyecto político ligado a las élites criollas, quienes habían sido cultivadas en las letras. Esto se dio a partir de la posición de privilegio que tenían en la época” (Villa, 2010, p. 1).

La literatura de corte indigenista desplazaba la posibilidad de nacimiento de una agencia discursiva de los indígenas en tanto actores políticos. Ellos solo eran recogidos como parte de la obra literaria que debía tener un estilo correspondiente, en cierta manera, con el costumbrismo que ayudó a poner al otro racializado en el centro de un estilo de escritura literaria que lo seguía afirmando en la marginalidad que complejiza las relaciones sociales. En cierto modo se trataba de afirmar el lugar de privilegio del hombre blanco-mestizo. En este caso, la usurpación actúa como una instancia sustituta de la voz del otro, de la imagen y, en general, de los significados del otro, encerrado e imposibilitado en la representación que hecha desde un yo, afirmado en la escritura. Por esto, "quien habla en el relato no es quien escribe en la vida, y quien escribe no es quien existe". Se trata, entonces, de poner de relieve la

7 Según Guerrero (2004), la usurpación se da "cuando la cultura y sus construcciones simbólicas pueden ser instrumentalizadas ya sea para el ejercicio del poder y la dominación o ser empleadas para su impugnación" (p. 43). 
pregunta de los estudios poscoloniales y decoloniales, cuando entran a preguntarse: ¿quién representa a quién?

Los textos seleccionados para entrar a considerar los elementos de la usurpación a través de la "cadena de sustitución" se perciben como un esfuerzo por alimentar la puesta a punto de una memoria artificial que pretende hablar por el otro. Aquellos que escriben en estos textos son personas que habitan los Andes y que en ese relacionamiento intentaron dar cuenta de un cruce de fronteras culturales, donde lo propio y lo extraño se diluye a partir del hecho de habitar una "zona de contacto". Ello se manifiesta en la escritura de quien habita un cuerpo blanco-mestizo, urbano y letrado, donde lo que cuenta es un con-sentimiento de experiencias, marcadas por el continuo de la marginalidad, la exclusión y la dominación. Contradictoriamente, en estos textos literarios también se celebra la vida de los cuerpos que han sido negados a través del recurso de la escritura, la cual se convierte en una literatura que es construida desde las periferias o, como diría Ignacio Echeverría, "literaturas pequeñas”. A continuación se consideran algunos textos que retratan la reflexión presentada hasta el momento.

\section{"La piedra y la cruz", de Ciro Alegría}

Este cuento nos presenta una interacción generacional entre un indio viejo y un niño descrito como blanco, aunque por las venas de la sangre de la mamá corran gotas de sangre india. Se destaca del cuento la descripción de las facciones físicas de los personajes, así como el paisaje de los Andes: se convierte en un contexto triste y desolado, con grandes montañas escarpadas y pedregosas que van recorriendo el viejo que guía al niño. En este recorrido, los dos tiene que enfrentar el soroche o mal de montaña.

El niño es representado como un personaje blanco que vive dos mundos: el primero tiene que ver con el padre, y el segundo, con el mundo de la madre que es del norte del Perú, es decir, es gente "chola". La interacción con algunos viajeros que el indio viejo y el niño encuentran en el camino refleja las creencias cristianas, en las que se saluda según la sujeción a Dios y la Virgen como instancias máximas. Los viajeros, en un acto "generoso" y de amistad, le ofrecen al niño aguardiente de caña, y este acepta porque le habían dicho que era bueno para esas travesías. Después cada quien sigue su camino.

Después de un tiempo del viaje, el indio viejo le comparte al niño la tradición de coger piedras medianas y cargarlas para ponerlas en la cruz del alto. El guía le pregunta al 
niño que si desea coger una piedra para ponerla en la cruz; la respuesta del niño es que no, y esto se debe a la influencia del padre, quien le había dicho que no colocará piedras en ese lugar, que eso eran cosas de indios y cholos, de gente ignorante. El viejo le explica el significado de las piedras puestas en la cruz, mientras el niño pensaba en la mamá, que sí era devota y llevaba una cruz en el pecho. Si le hubiera preguntado en ese caso a ella, otro hubiera sido el consejo.

El viejo indio le insiste al niño y este se debate entre la creencia de la mamá y las posturas racionalistas del papá. Le cuenta de todas las bondades y los infortunios que han padecido las personas que desafían esa tradición. Le habla del significado de las piedras y lo valiosas que son. Finalmente, el indio viejo saca dos piedras de la alforja, una la pone sobre ella y la otra la toma en su mano para hacer su ofrenda; seguidamente, el niño la coge y silenciosamente se acerca a poner la suya.

De este cuento se resalta la formación de la "conciencia contradictoria", resultante de la incomunicabilidad existente entre la cultura del padre y la cultura de la madre del niño; es la formación de una identidad mestiza que presenta un lado oscuro del cual se esconde o del cual no se pude hablar o vivir como tal. También se resalta el diálogo intergeneracional que se genera en el viaje, el cual se percibe como un rito de paso que el niño tiene que afrontar de una u otra forma. En este cuento se refleja la imposibilidad de encausar unas relaciones interétnicas, sobre todo cuando las barreras trazadas por la monocultura no se desplazan.

\section{"Boletín y elegía de la mitas", de César Dávila Andrade}

Es un texto en el que se comienza evocando la fuerza colectiva de un poder otorgado por la memoria de los ancestros, articulados alrededor de la deidad mayor de Pachacámac, señor de los universos de los quechuas. También se mencionan personajes emblemáticos de la resistencia. En medio de la evocación de la fuerza de la memoria, se expresa lo distante de la tradición por medio de la pérdida. Esto sucede mientras los indios o indígenas son explotados y maltratados por los señores varicochas. Las mujeres indias son obligadas a trabajar y a tener relaciones sexuales contra su voluntad. De esta acción torturante nace el “matizo y verdugo venidero".

En este cuento se narra cómo los indios e indias son dominados y explotados sin ninguna consideración; solo reciben insultos y maltratos, que pasan a ser torturas grabadas en la piel, como una memoria escrita con la tinta de su sudor y sangre. 
Tanta es la humillación y violencia a las cuales son sometidos los indígenas, que el narrador implora a Pachacamac para que les arrebate la vida: es mejor morir. En un pasaje cuenta cómo su hija, convertida a la fuerza en mujer del alférez Quitanilla, pierde dos hijos como efecto de los latigazos. Ante tanto dolor, la india le pide a su marido que le "tuerza los brazos de los guaguas", porque no quiere que se conviertan en mitayos, que sean los indios que se encuentran al servicio de la mita. El quebrar los brazos tiene los efectos de terminar con la vida de los niños, quienes en quechua son nombrados como guaguas.

La figura de los curas católicos se representa como seres parecidos a los diablos. Ellos contribuyen a tejer la doctrina de la iglesia, que acaba con la creencia de la deidad propia de Pachacámac. La explotación es tal que el narrador cuenta cómo fue castigado durante un año y cuarenta días, obligado a trabajar todos los días sin importar que fuera viernes santo; sin embargo, a los señores no les importaba la tradición religiosa cuando se trataba de forzar a los indios a hacer el trabajo.

Contrariamente, los indios tenían que agradecer a un Cristo que les habían traído entre lanzas, banderas y caballos. A la vez, el indio tenía que agradecer al verdugo besándole la mano que sostenía el látigo. En este contexto, el indio aprendió a contar en la lengua del señor, contando uno a uno los latigazos propinados: 1, 2, 3, 4, 5, 6, 7....? "Con mi dolor y mis llagas" el indio aprende, pues después de todo el sufrimiento, tenía que expresar: "Dioselopaguí, amito".

El mestizo aparece como una persona cruel que odia a los indios. Es el caso del mestizo Juan Ruiz, que cogió una cáscara de huevo que había puesto en la candela y se la puso a Dulita, que era una india que había dejado caer un plato. Como respuesta, el mestizo le pateó las nalgas, a lo que ella contestó: “caraju”. El mestizo, como represalia, le puso la cáscara de huevo bien caliente en la boca, lo que le produjo quemadura y sangrado. Después de eso, la india Dulita duró cinco días sin comer y finalmente la encontraron muerta en "la acequia de los excrementos".

En este contexto colonial, la injusticia era tal con los indios que cuando se moría una vaca o una oveja y esta se encontraba en estado de descomposición, llena de gusanos, los indígenas la arrastraban hasta donde el señor, para que él la viera. Luego, les hacía comprar la carne inundada de gusanos y los obligaba a comerla, sin importar lo avanzado de su estado de descomposición. Cuenta el narrador que los indios debían 
trabajar un año más para cubrir el costo de la carne podrida: trabajo y trabajo hasta morir, "convirtiéndose en gusano, ese mismo que devora a los amos y al mitayo".

En el contexto del cuento, el dolor al que es sometido el cuerpo de los indios es tal, que cuenta que una vez un indio llamado Tomás Quitumbe de Quito se dio a la fuga por el temor, pero fue atrapado y castigado brutalmente. Después sus heridas fueron llenadas con ají y con sal, y el pobre ser humano se quejaba retorciéndose del dolor y exclamaba: "amo viracocha, amo viracocha”. Nadie le oyó morir. Quiere decir que nadie pudo intervenir, y por eso se hicieron que no escuchaban al pobre indio quejarse del dolor producido.

Finalmente, el cuento termina cuando el indio narrador pasa trabajando dos años y ocho meses en una mina. Cuando salió de ella, se encontró con el cadáver de Pedro Axitimbay, el hermano; encontró su pecho como un hueso pelado, es decir, un hueso descubierto: "Esa persona era un hueso plano. Era un espejo", ante lo cual se miró y se reconoció: “¡Yo era él mismo!”. En este mismo momento evocó la memoria de sus antepasados, la deidad superior, los abuelos, los padres, las madres y los hijos, también a sus verdugos, y expresó: “¡Vuelvo, azome! ¡Levántame después del tercer siglo de entre los muertos!”.

Este cuento termina con una evocación a la memoria de una utopía que recorre los Andes, que reza: "Volveré y seré millones". Por eso, el cuento termina con las palabras: “ ¡Soy! ¡Somos! ¡Seremos! ¡Soy!”.

El texto refleja el dolor de una raza que es proyectada como vencida, raza incapaz de sobreponerse a las vicisitudes que le impone la dominación de los blancos-mestizos. Esta imagen pesa en la representación del otro, considerado como un cuerpo diezmado, resignado a la voluntad de dominación, conciencia abdicada y erradicada de cualquiera posibilidad de resistencia. La presentación que se hace del indio posiciona una imagen harapienta: cuerpos hiperexpuestos como otro antiséptico, repudiado y sometido a la consideración o mejor salvación que le brinda la crueldad del señor hacendado.

\section{"El sol bajo las patas de los caballos", de Jorge Enrique Adum}

Se trata de un texto teatral en que se representa la modelación por la fuerza que oprime la libertad de los cuerpos, por medio de la institucionalidad de la mal llamada 
"conquista" y de la colonización, que después se convertiría en un continuo correspondiente a un "patrón configurado" que hace parte de la colonialidad. Esta obra se caracteriza por no manejar una secuencia lineal de tiempo, sino una relación entre tiempos que son reactualizados en la medida que las voces se van presentando a lo largo de la obra. En este sentido, es una obra que juega con el pasado y el presente, llegando a imbricarlos, sin respetar la consideración moderna, donde se asume el tiempo de forma progresiva y acumulativa.

Es la puesta en escena donde actúa un propietario, un cura y un policía. La intervención se cruza con otros sucesos de la vida andina durante la llegada de Pizarro y su expedición, que termina por engañar y asesinar a Atahualpa, después de quitarle el oro. Es la destrucción del Imperio inca. Todo ese trágico destino fue adivinado por un sacerdote que habla con Huaynacapac, que le informa de la gente que anda en casa flotante en el mar grueso, gente con pelo en la cara y de metal. Esa gente que anda navegando por las aguas gruesas, o sea, el mar, pregunta por el inca y dónde queda el Cuzco. El otro correo le comenta cómo ellos les gritan a esos hijos de mala madre. En ese momento, se presentan unas voces que conectan con el tiempo actual, en el que ellos, o sea, la gente de Pizarro, representan a los policías, gente del imperio. Esta gente le manda a Huaynacapac un regalo de palo que se parece a ellos: "dicen que se llama dios".

En el texto se cuenta cómo Pizarro hace su primer intento por llegar al centro del Imperio inca en los Andes, pero tiene que desistir y pedirle ayuda a la reina: le solicita un título real, previo acuerdo de la repartición de las riquezas que encuentre en sus expediciones. Como parte del arreglo se acuerda que debe de ir, en esta expedición, un eclesiástico para la evangelización de todos los naturales.

En pleno desarrollo de la expedición, Pizarro se encuentra con unos indios que piden hablar con él, para que le ayuden a derrotar a sus enemigos, que le han destruido sus pueblos al norte, los tumbes. Estos dicen que si le entregan a Atahualpa, serán bien recibidos. En ese pasaje de la obra, Pizarro termina por aceptar y lanza unas amenazas contra Atahualpa. Después de este pasaje se presenta un diálogo que recrea un entretiempo en el que se reactualiza la obra en la contemporaneidad.

8 Sostengo que la conquista no fue total y que pese al dominio de los españoles, los indígenas pudieron mantener una conciencia de reacción frente a los procesos de domesticación extendida sobre el cuerpo. Autores como Enrique Dussel y Anibal Quijano han llamado la atención sobre poner a circular la denominación "conquista". 
En las siguientes escenas recreadas aparece Atahualpa con Rumiñagui, conversando. El primero tiene la inquietud por conocer a los visitantes, mientras el segundo le advierte sobre lo arriesgado que puede resultar: lo mejor es atacarlos y vencerlos. Atahualpa no es disuadido de su intención y se presta al encuentro, pero es capturado por los visitantes. En toda esta expedición aparece un personaje: Felipillo, un indígena traductor de los viajeros que actúa de forma ladina, es decir, en favor de los invasores. También aparece Valverde, que es un representante de la Iglesia y la acompaña en toda esta travesía por la codicia del oro. El papel de este personaje es incitar al sometimiento violento de los indios, tanto es que en un pasaje comenta:

\begin{abstract}
Si no lo hicieseis, certifico que con la ayuda de Dios yo entraré poderosamente contra vosotros, $\mathrm{y}$ os haré guerra por todas partes y maneras que pudiere, $\mathrm{y}$ os sujetaré al yugo y obediencia de la Iglesia y de Su Majestad, y tomaré vuestras mujeres e hijos y los haré esclavos, y como tales los venderé, y os tomaré vuestros bienes, y os haré todos los males y daños que pudiese; y protesto que las muertes y daños que de ello se recrecieren sea vuestra culpa y no de $\mathrm{Su}$ Majestad, ni de estos caballeros que conmigo vinieron ni mía.
\end{abstract}

Toda esta alusión se hace de parte de Valverde, en nombre de Dios y de la fe que condena a los otros, que son nombrados como amenaza al orden explicativo de lo humano. Es el cinismo de la acción que históricamente ha negado la diversidad étnica y cultural. En este caso, otro pasaje que refleja el cinismo de los personales cegados por la ambición del oro es cuando Pizarro toma preso a Atahualpa. El Ibérico llegó a proferir las siguientes palabras: Acercándose a Atahualpa: Creedme, Majestad, que lamento de veras lo sucedido. En estos momentos de pesar os reitero mis sentimientos de simpatía y mis intenciones de amistad". Este diálogo refleja el cinismo de quien agrede y, a la vez, expresa su sentimiento de admiración.

Finalmente, Atahualpa le propone a Pizarro todo el oro que ellos tenían, con el fin de que lo liberen; el primero acepta, pero después de tener el oro falta a su palabra y asesina a Atahualpa. Después sigue una reactualización del tiempo en el sentido presente y el significado de las luchas en los pueblos de América Latina.

Este texto maneja una trama interesante que refleja el tejido de un entretiempo en el que el autor se basa en documentos históricos para desarrollar todo la obra. De esta 
manera, podemos preguntar por el límite de la narración en el sentido de lo real y lo imaginado, desde la inventiva de quien recrea a través de un estilo literario propio.

\section{Avanzando sobre las emergencias}

Debo aclarar que este artículo corresponde a un trabajo desarrollado a partir de los estudios culturales latinoamericanos decoloniales. En ellos, la pregunta por el problema de la producción y representación del conocimiento está a la orden del día, no solo como objeto de estudio, sino como posibilidad de entrar a interrogar el conocimiento y la sociedad desde unos referentes distintos que permitan poner en evidencia el problema de las asimetrías que se generan con las representaciones. También se debe considerar que la producción del sentido se genera a partir de procesos guiados a través de artefactos como la literatura y otras elaboraciones que no escapan a la cuestión política.

La producción del mal-decir ha sido alimentada a través de las fuentes patrimoniales de lo nacional, centralizado en la monocultura que promociona y esconde su verdaderos ánimos de condena. El problema de la cadena de sustitución actúa como una estrategia política que conlleva "hablar a favor de". La cadena de sustitución se genera cuando se habla por, de, en y sobre el otro, lo que produce una sensación de estar hablando o, mejor, representando a las y los cuerpos que no se manifiestan por sí mismos. Es la escritura - y la literatura, en este caso- una instancia de "simulador cognitivo" que modula la relación entre lo representado por la escritura como un "espejo de la realidad" y una fisión que compromete la existencia negada de los otros.

\section{Referencias}

Abril, G. (2007). Análisis crítico de textos visuales. Madrid: Síntesis.

Arguedas, A. (1937). Pueblo enfermo y la representación de la otredad. Santiago: Ercila.

Anderson, B. (1997). Comunidades imaginadas. México: Fondo de la Cultura Económica.

Bonfil, G. (1991). Pensar nuestra cultura. México: Alianza. 
Burke, P. (2001). Visto y lo no visto, el uso de la imagen como documento histórico. Barcelona: Crítica.

Calvo, F. (1999). Cratilo. En Los clásicos de la Grecia y Roma. Madrid: Planeta.

Castoriadis, C. (1989). La institución imaginada de la sociedad. En Colombo, E. El imaginario. Montevideo: Altamira.

Colombo, E. (1989). El imaginario. Montevideo: Altamira.

Duschatzky, S. y Skliar, C. (2001). Los nombres de los otros. Narrando a los otros en la cultura y en la educación. En Larrosa et al. Habitantes de Babel. Políticas y poéticas de la diferencia. Barcelona: Laertes.

Dussel, E. (2004). Sistema-mundo y "transmodernidad". En Dube, S., Dube, I. y Mignolo, W. (Comps.). Modernidades coloniales. México: El Colegio de México.

Guarda, B. R. y Villa, W. (2010). La raza vencida: una invención para contener a los otros en los Andes. Quito: Universidad Andina Simón Bolívar.

Guerrero, P. (2005). Usurpación simbólica, identidad y poder. Quito: Universidad Andina Simón Bolívar.

Estermann, J. (1998). Filosofía andina. Estudio intercultural de la sabiduría autóctona andina. Quito: Abya-Yala.

Hulme, P. (1996). La teoría poscolonial y la representación de la cultura en las Américas. La Habana: Casa de las Américas.

Lozano, J. (2000). Introducción a las ciencias sociales. México: Plaza Valdés.

Mignolo, W. (2003). Historias locales/diseños globales. Madrid: Akal.

Palmer, B. G. (2000). Lingüística cultural. Madrid: Alianza.

Rama, Á. (1998). La ciudad letrada. Montevideo: Arca.

Sáenz, J., Saldarriaga, Ó. y Ospina, A. (1997). Mirar la infancia: pedagogía, moral y modernidad en Colombia, 1903-1946. Bogotá: Foro Nacional por Colombia. 
Soler, S. y Pardo, N. (2007). Discurso y racismo en Colombia. Cinco siglos de invisibilidad y exclusión. En Van Dijk, T. Racismo y discurso en América Latina. Barcelona: Gedisa.

Spivak, C. G. (2003). ¿Puede hablar el subalterno? Revista Colombiana de Antropología, 39. Bogotá.

Sullà, E. (1998). El debate sobre el canon literario. En El canon literario. Madrid: Arco.

Vich, V. y Zavala, V. (2004). Oralidad y poder. Bogotá: Norma.

Villa, W. (2010). La invención de lo indígena y lo afro en la literatura latinoamericana: una memoria de los lugares. Quito: Universidad Andina Simón Bolívar.

Villa, W. (2012). De los avatares de la memoria a los silencios e indiferencias frente a los otros. En Trayectorias de pueblos y procesos de investigación en diversidad cultural. Bogotá: Universidad Francisco José de Caldas.

Villa, W. y Villa, E. (2008a). Descentración del canon y la valoración de las emergencias posibles: la cuestión del lugar de enunciación de lo silenciado. Cartagena: Universidad de Cartagena - Universidad del Atlántico.

Villa, W. y Villa, E. (2008b). La cultura en el marco de la educación: acciones posibles para una construcción de lo "otro". Revista Educación y Cultura, 79.

Villa, W. y Villa, E. (2010). La pedagogización de la oralidad en contexto de afirmación cultural de las comunidades negras del Caribe seco colombiano. Cartagena: Universidad de Cartagena - Universidad del Atlántico.

Villa, W. y Villa, E. (2011a). Desarrollo y mundos desencontrados en el actuar representado desde los borde. Revista Anthropos, 230.

Villa, W. y Villa, E. (2011b). La cátedra de estudios afrocolombianos: una posibilidad de descolonización del lenguaje en el Caribe seco colombiano. Revista Nómadas, 34. 